\title{
An investigation into the possible beneficial effects of milk hydrolysates on insulin secretion and metabolic function
}

\author{
S. Flynn ${ }^{1,5}$, C. Gaudel ${ }^{1,5}$, A. Nongonierma ${ }^{2,5}$, M Bhate ${ }^{2,5}$, R. J. Fitzgerald ${ }^{2,5}$, S. Maher ${ }^{3,5}$, A. Baird ${ }^{3,5}$, \\ P. Newsholme $e^{1,5}$ and L. Brennan ${ }^{4,5}$ \\ ${ }^{1}$ School of Biomolecular and Biomedical Sciences, Conway Institute, University College Dublin, Belfield, Dublin 4, \\ Republic of Ireland, ${ }^{2}$ Department of Life Sciences, University of Limerick, Limerick, Republic of Ireland, \\ ${ }^{3}$ School of Veterinary Medicine, Veterinary Science Centre, University College Dublin, Belfield, Dublin 4, \\ Republic of Ireland, ${ }^{4}$ Institute of Food and Health, University College Dublin, Belfield, Dublin 4, Republic of Ireland, \\ ${ }^{5}$ Food for Health Ireland
}

In recent years, extensive research has provided evidence to suggest that bioactive peptides derived from food may exert beneficial effects on human health ${ }^{(1)}$. Bioactive peptides have been identified within the amino acid sequences of bovine milk, which are released upon enzymatic hydrolysis using digestive enzymes ${ }^{(1)}$. Moreover, milk derived bioactive peptides have previously been reported to generate beneficial effects on human cardiovascular, immune and nutrition systems ${ }^{(2)}$. The objective of this study is to determine if milk derived hydrolysates have an effect on insulin secretion and glycemic function by firstly examining the possible insulinotropic properties on pancreatic $\beta$-cells in vitro and in vivo using an ob/ob mouse model. To investigate the insulinotropic effects of milk hydrolysates in vitro, BRIN-BD11 cells were treated with basal levels of glucose $(1.1 \mathrm{mM})$ for 40 minutes prior to stimulating with $16.7 \mathrm{mM}$ glucose and Hydrolysate A $(1 \mathrm{mg} / \mathrm{ml})$ for 20 minutes. A two-tiered model with human intestinal Caco-2 cells and pancreatic BRIN-BD11 cells were used in bioavailability studies. Hydrolysate A at a concentration of $1 \mathrm{mg} / 1 \mathrm{ml}$ stimulated insulin secretion (5.5 ng insulin/mg protein) from BRIN-BD11 cells; the induction of insulin release was significantly different when compared to the control of unhydrolysed protein $(0.265 \mathrm{ng}$ insulin $/ \mathrm{mg}$ protein $),(P<0.005)$. Further analysis revealed that Hydrolysate A stimulated insulin release in a dose dependent manner $(1.5 \mathrm{ng}-10 \mathrm{ng}$ insulin/mg protein at concentrations of $0.01-5 \mathrm{mg} / \mathrm{ml})$. The bioavailability experiments demonstrated significant transport of the bioactive sample through the Caco-2 layer. After 4 hours, Hydrolysate A at $50 \mathrm{mg} / \mathrm{ml}+100 \mathrm{mM}$ glucose induced $4.6 \mathrm{ng}$ insulin/mg protein from BRIN-BD11 cells as compared to $1.5 \mathrm{ng}$ insulin/mg protein induced by the control of $100 \mathrm{mM}$ glucose $(P<0.005)$. The in-vivo effect of this hydrolysate is currently being assessed in an ob/ob model of diabetes. In conclusion, Hydrolysate A is a potent inducer of insulin secretion, which is bioavailable in a two-tiered co-culture model. Future work will be directed towards encompassing this bioactive into a functional food used to aid glycemic management.

1. FitzGerald RJ, Meisel H (2003) Milk protein hydrolysates and bioactive peptides 2 .

2. Fox PF, McSweeney PLH (eds) Advanced Dairy Chemistry. Volume 1. Proteins. Part B, vol 1. 3rd edn. edn. Kluwer Academic/ Plenum Publishers, New-York, pp. 675-698. 